\title{
I -- Pareceres da Consultoria Jurídica do DASP
}

\section{ACUMULAÇÃO}

De proventos com gratificação de RETIDE.

A circunstância, no caso, de o servidor perceber, cumulativamente, o provento da aposentadoria com o vencimento do cargo de Engenheiro do Departamento Niacional de Produção Mineral $\square$ Ministério das Minas e Energia - não é impeditiva da possibilidade de receber êle gratificação por tempo integral.

$\mathrm{O}$ que caracteriza o pagamento da citada gratificação é a dedicação exclusiva ao desempenho das atividades afetas ao cargo que ocupa. E a aposentadoría, de que é também detentor, não o impede, de forma alguma, de dar aquela dedicação exclusiva.

Processo $n^{\circ}$ 1.529-67 - DASP.

Inclusão em RETIDE de funcionário titular de dois cargos. afastado de um dêles.

O que impede a inclusão do servidor no regime de tempo integral e a conseqüente percepção da gratificação não é a titularidade de duas situações, pois que êle de uma delas se afasta conservando-a, no entanto, mas sem teccber qualquer vencimento ou salário, enquanto na outra estiver sob aquêle regime. O recebimento de dois vencimentos ou salários com a gratificação oriunda de tempo integral, em função de um dos cargos, é que não se concilia.

Processo $n^{\circ}$ 9.984-66 - DASP.

Funcionário federal colocado à disposição de Govêrno estadual (cargo em comissão).

O cargo ocupado pelo funcionário, na administração federal, é de natureza técnico-cientifica, o que the enseja a aplicação do art. 121, parágrafo único, da Lei $\mathrm{n}^{\circ} 1.711$, de 1952. No caso, entretanto, uma vez que a requisição foi feita para exercício de cargo em comissão, não the poderá ser pago o vencimento do cargo efetivo, salvo se, pelo cargo estadual, apenas receber uma gratificação.

Mesmo que o cargo estadual fôsse considerado de natureza técnico-cientifica, privativo de médico, que permitisse acumulação com o cargo de Médico-Sanitarista do Ministério da Saúde, nos moldes determinados no art. 97 da Constituição Federal, a percepção conjunta de vencimentos importaria no conseqüente exercicio de ambos os cargos por parte do servidor, não havendo a hipótese de percepção cumulativa de vencimentos, ocorrendo o afastamento do servidor do exercício de um dos cargos.

Por outro lado, a pretensão do suplicante de continuar a perceber a gratificação de tempo integral, que vinha, antes do afastamento, recebendo no $\mathrm{Mi}$ nistério da Saúde, não encontra qualquer acolhida em dispositivo legal.

$$
\text { Processo } \mathrm{n}^{2} \text { 8.372-67 - DASP. }
$$

\section{AFASTAMENTO}

Decreto $n^{2}$ 59.676, de 1966. Interpretação dos $\$ \S 1^{\circ}$ e $2^{\circ}$ de seu art. 34 .

Condição para aplicação do RETIDE a ocupante de cargos de professor do magistério superior e de engenheiro do DNER. A aplicabilidade à espécie do art. 16 e setis $\$ \xi 1^{\circ}$ e $2^{\circ}$ do Decreto numero 60.091-67.

A opção pelo regime de tempo integral e dedicação exclusiva por parte 
de professor universitário, que acumula legalmente cargo público, deverá determinar o afastamento dêste, enquanto durar o regime excepcional, e não a exoneração do cargo.

$$
\text { Processo } n^{\circ} \text { 10.519-67 - DASP. }
$$

\section{AFASTAMENTO REMUNERADO}

\section{Licença à funcionária gestante.}

Reportando-se a pronunciamento emitido no processo 2.571-67, segundo o qual o relacionamento constante no art. 14 do Decreto 60.091-67 "não é excludente de outras situações, muito menos das que estão autorizadas em lei, à semelhança do que consta do art. 57 da Lei $n^{5}$ 4.242-63", a Consultoria Juridica do DASP entendeu que a licença à gestante não interrompe o pagamento da gratificação de RETIDE, por the parecer que a referida licença está implicitamente enquadrada no mandamento cstabelecido no art. 57 dia Lei 4.242 .

$$
\text { Processo } n^{\circ} 4 \cdot 390 .-67 \text { - DASP. }
$$

Faltas (até três dias) abonadas nos têrmos do art. 123 do Estatuto dos Funcionários (Lei $n^{\circ} 1.711$ de 28-10-52).

Deve ser paga a gratificação de RETIDE à funcionária que tiver faltas abonadas de acôrdo com o artigo 123 do Estatuto dos Funcionários, de vez que não se verifica pròpriamente um afastamento do serviço, pois a lei, objetivando uma eventual doença do servidor, abona o não comparecimento ao serviço, sem que daí resulte qualquer desconto salarial ou de gratificações para o funcionário. Se nesses dias nenhum desconto houver, não há que se falar em falta ou afastamento pròpriamente ditos.

$$
\text { Processo } \mathrm{n}^{0} \text { 2.571-67 - DASP. }
$$

Falta ao serviço para a prestataçño de prova ou exame (Artigo 158 do Estatuto dos Funcionários - Lei $n^{\circ}$ 1.711, de 28-10-52)

Desde que o comprove devidamente, Q funcionário em RETIDE que dei- xar de comparecer à repartição para se submeter a prova ou exame fará jus à gratificação correspondente ao referido regime.

$$
\text { Processo } \mathrm{n}^{9} \text { 2.571-67 - DASP. }
$$

\section{CONSELHOS DOS IAPS}

Aplicabilidade do RETIDE.

Nos Conselhos Administrativos e nos

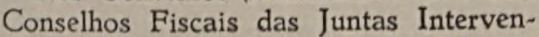
toras das instituições da Previdência Social o RETIDE só é aplicável aos Presidentes dos Conselhos Administrativos, consideradas as funções executivas que lhes competem no exercicio das atribuições de Presidente da res* pectiva autarquia.

Processos ns. 6.079-67 - DASP e 9.371-67 — DASP.

\section{DEDICAÇÃO EXCLUSIVA}

Incompatibilidade com o exerctcio de tarefas estranhas às atribuições do cargo.

O objetivo do RETIDE é possibilitar total concentração do servidor nas tarefas próprias do seu cargo ou de sua função, o que não seria al. cançado com o desvio para qualquer outra atividade estranha.

$$
\text { Processo } \mathrm{n}^{\circ} \text { 10.776-66 - DASP. }
$$

\section{LICENÇA À GESTANTE}

Direito ao recebimento da gra* tificaçâo durante o respectivo periodo.

A licença concedida à funcionária gestante não interrompe $\circ$ pagamento da gratificação de RETIDE.

\section{Processo $n^{\circ}$ 4.390-67 - DASP.}

MILITAR EM FUNÇÃO CIVIL

\section{Aplicabilidade do RETIDE.}

Se o militar estiver percebendo o vencimento do cargo $\mathrm{em}$ comissão que ocupe ou a gratificação de função que exerça por fôrça de determinação legal expressa, fará jus à gratificação de RETIDE se fôr do interêsse da Administração aplicar ao cargo ou à 
função gratificada tal regime nas mesmas condições do ocupante civil.

Processo $n^{\circ}$ 3.827-67 - DASP.

\section{MINISTÉRIO PÚBLICO}

Possibilidade, em tese, de aplicação do RETIDE a servidores da Secretaria da $1^{\circ}$ Subprocuradoria-Geral da República.

Com exceção dos membros do $\mathrm{Mi}$ nistério Público Federal, pròpriamente ditos, os quais, por fôrça de lei, não podem submeter-se ao regime de tempo integral e dedicação exclusiva, aos demais não é defesa essa incidência, desdc que satisfeitas as disposições regulamentares próprias.

Processo $n^{\circ}$ 6.139-67 - DASP.

\section{OPÇÃo}

Compatibilidade com o disposto no item III, art. 101 do Decreto-lei $n^{\circ} \quad 200-67$.

A simples inclusão de determinado cargo em comissão ou função gratificada em RETIDE não autoriza a presunção absoluta do interêsse administrativo nesse regime. Vários fatôres têm de ser cotejados para êsse juizo, inclusive até o maior proveito $\mathrm{em}$ contar com determinado ocupante que não pode submeter-se a êsse regime especial de trabalho. É matéria, pois, de apreciação subjetiva, tendo em vista o caso concreto, que se não pode furtar às ponderações pelo órgấo a que o cargo ou a função pertencem. Dai a continuidade de vigência da preceituação constante do $\S 3^{\circ}$ do art. 27 do Decreto $\mathrm{n}^{\circ}$ 60.091, de 1967, cuja colisão com o comando juridico expresso no artigo 101 do Decreto-lei número 200, de 1967, é apenas aparente.

Processo $n^{\circ}$ 252-68 - DASP.

\section{If - DECISOES DA COTIDE}

AFASTAMENTO REMUNERADO

Viagem de servidor em RETI$D E$ ao estrangeiro.

O pagamento da gratificaçăo referente a êsse regime nấo deve ser interrompido, desde que a viagem ao ex- terior esteja vinculada ao respectivo programa de trabalho.

Processo n? 980-66 - COTIDE.

Observação: Posteriormente, o Decreto $\mathrm{n}^{\circ}$ 61.775, de 24-11-67, estabeleceu que a viagem do servidor ao exterior também é permissivel quando justificada como condição para melhor exercicio do cargo que ocupa, em futuro imediato.

Faltas abonadas nos têrmos do $\S 2^{\circ}$, art. 11 do Decreto 49.974-A, de 21-1-61 (Código Nacional de Saúde).

Desde que se comprove a permanênc:a em isolamento ou quarentena, determinada pela autoridade competente para evitar a propagação de doença transmissivel, o funcionário pôsto em tal situação terá direito à percepção da gratificação do RETIDE referente aos dias de afastamento do serviço.

Processo $\mathrm{n}^{\circ}$ 956-67 - COTIDE.

\section{AGREGADO}

Sua inclusão em RETIDE ou cm RESEX.

Segundo entendimento firmado pela COTIDE, poderá ser proposto em tabela de RETIDE o agregado que:

a) se encontre no exercicio de cargo em comissão ou função gratificada;

b) embora não preenchendo uma das condições da alinea anterior, fôsse titular de cargo técnico na ocasião da agregação.

Estabeleceu a COTIDE, ainda, que o agregado não enquadrável em nenhuma daquelas situações sòmente poderá participar de tabela destinada a RESEX.

Processo $\mathrm{n}^{\circ}$ 716-67 - COTIDE (Parecer da C.J. do DASP no processo 7.518-66).

\section{ASSESSORAMENTO}

Sua conceituaçăo em relação a RETIDE.

Para efeito de inclusão em RETIDE deverá ser distinguido o assessoramento a que se refere a Lei 3.780 , de 
1960, daquele que é desempenhado pelo ocupante de cargo em comissão ou função gratificada previsto no art. 5 ? do Decreto-lei $n^{\circ} 81$, de 21-12-66.

Processo $n^{\circ}$ 56-67 - COTIDE.

CARGOS EM COMISSÃO E FUNÇÕES GRATIFICADAS SEM EXISTÊNCIA. LEGAL

Impossibilidade de sua inclusão em RETIDE.

O regime de tempo integral só pode ser aplicado a cargos em comissão e funções gratificadas legalmente criados.

Processo $n^{2}$ 316-66 - COTIDE.

CESSAÇÃO DO RESEX

Aplicabilidade do art. 28 do Decreto $n^{9} 60.091$, de 18-1-67.

Conquanto o mencionado dispositivo se refira expressamente ao RETIDE, deve ser êle aplicado ao RESEX, no que couber, já que inexistem preceitos próprios em relação a êste.

Processo n: 391-66 - COTIDE.

\section{CHEFIAS MILITARES \\ Inaplicabilidade do RETIDE.}

$O$ regime de tempo integral e dedicação exclusiva de que cogita o Decreto $n^{\circ} 60.091$, de 18-1-67, não se aplica às chefias militares. Entretanto, independentemente da natureza da chefia, isto é, civil ou militar, o referido regime pode ser aplicado ao pessoal civil enquadrável no art. $1^{\circ}$ do citado decreto.

\section{Processo $n^{\circ}$ 981-66 - COTIDE. \\ COMPULSORIEDADE DE RETIDE PARA CARGOS EM COMISSÃO OU FUNÇÕES GRATIFIC $A D A S$}

Op̧̧ão prevista no Regulamento.

Nos têrmos do $\S 3^{\circ}$ do art. 27 do Decreto $n^{\circ} 60.091-67$, os ocupantes de cargos em comissão ou funções gratificadas só poderão eximir-se de participar do RETIDE quando invocados impedimento legal ou motivios justos, a juizo do Ministro de Estado ou do dirigente da autarquia ou do órgão diretamente subordinado ao Presidente da República, sob cujas ordens servirem.

Processo n $575-67$ - COTIDE.

CONSELHO FEDERAL OU REGIONAL . DE ODONTOLOGIA

Orgão de deliberação coletiva.

Dirigente do Serviço Nacional de Fiscalização da Odontologia em RETIDE pode exercer o mandato de membro do Conselho Federal ou de Conselho Regional de Odontologia.

Processo $n^{\circ}$ 889-67 - COTIDE,

CURSOS E RETIDE

Condições para que o servidor possa freqüentá-los.

O funcionário colocado em RETIDE só poderá freqüientar curso se houver correlação entre o programa de trabalho que motivou o referido regime e a natureza do curso e se ficar comprovado o interêsse do órgáo em que serve em sua freqüência ao mencionado curso.

Processo $n^{\circ} 877-67$ - COTIDE.

\section{DEDICAÇÃO EXCLUSIVA}

Funcionário em RETIDE náo pode exercer atividades particulalares, profissionais, temuneradas, tenham ou não caráter empregaticio.

A dedicação exclusiva, inerente ao regime de trabalho em causa, obriga c servidor a êle submetido a dedicar tôda a sua atividade, seu esfôrço, seus interêsses ao serviço público, ficando, assim, impedido de exercer outra atividade, pública ou particular, mesmo que não tenha caráter empregatício.

Processo $n^{\circ}$ 813-67 - COTIDE.

DESCONTO SÔBRE A GRATIFICAÇÃO Aplicabilidade do art. 122 do Estatuto dos Funcionários.

Ante a inexistência de dispositivo expresso na respectiva regulamentação, 
deve ser aplicado, por analogia, ao servidor que chegue atrasado ao serviço ou dêle se retire antes do encerramento do expediente, o disposto no item II, art. 122, da Lei $n^{\circ} 1.711-52$ (Estatuto dos Funcionários).

Processo $n^{\circ}$ 27-67 - COTIDE.

\section{HORÁRIO ESPECIAL}

Aplicabilidade do RETIDE.

A jornada do servidor que tiver horário inferior a 40 horas será elevada a êsse limite minimo e será mantida a do que, por fôrça de ato regulamentar, tiver jornada fixada acima daquele limite.

Processo $n^{\circ}$ 580-66 - COTIDE.

\section{INÍCIO DO RESEX}

Fixação do direito à percepção do respectivo pagamento.

O servidor colocado em regime especial de horas extraordinárias passa a fazer jus à gratificação correspondente, desde que expedida a respectiva portaria, quando tal serviço efetivamente começar.

Processo $\mathrm{n}^{\circ}$ 391-66 - COTIDE.

\section{INÍCIO DO RETIDE}

Obrigatoriedade da assinatura do tềrmo de compromisso.

$\mathrm{O}$ direito à percepção da gratificação do RETIDE vigora, para cada funcionário, a contar do dia $\mathrm{cm}$ que êste assina o respectivo têrmo de compromisso.

Processo $n^{\circ}$ 695-67 - COTIDE.

\section{NNTERVALO PARA ALMOÇO}

periodo ninimo estabelecido.

Por não existir, atê o momento, dispositivo expresso sôbre o assunto na legislaçăo da administração pública federal propriamente dita, deve ser aplicầo à matéria o art. 71 da C.L.T., que estabelece o minimo de 1 (uma) hora para alimentação e repouso nas jornadas de trabalho a cuja duração exceda de seis horas.

Processo $n^{\circ}$ 933-67 - COTIDE.

\section{LICENÇA À GESTANTE}

Direito ao recebimento da gratiticação a partir da vigência do Decreto $n^{\circ}$ 57.744-66.

Os efeitos decorrentes da aprovação do parecer emitido no processo número 4.390-67 devem retroagir à data em que entrou em vigor o Decreto número $57.744-66$, ou seja, 17 de fevereiro de 1966.

Processo $n^{\circ}$ 917-67 - COTIDE.

\section{MAGISTÉRIO SUPERIOR}

Desacumulação de cargos em observância ao Decreto $n^{\circ} 59.679$ de 1966.

A desacumulação de cargos nos têrmos do Decreto $n^{\circ} 59.676$, que regulamentou o regime de tempo integral do pessoal docente de nivel superior, escapa ao exame da COTIDE.

Processo $n^{\circ}$ 475-67 - COTIDE.

\section{OPÇম̃}

Inaplicabilidads do art. $1^{\circ}$ \& $2 *$ da Lẹ $n^{\circ} 4.345-64$ à gratificaçắo de RETIDE.

A vista do que dispõem o art. $5^{\circ}$ do Decreto-lei 81-66 e o paráarafo único do art. $7^{\circ}$ do Decreto $n^{\circ}$ 60.091-67, não c्रh้อ o pagamento da gratificação do RETIDF com base na opcão prevista no $\delta 2^{\circ}$ do art. $1^{\circ}$ da Lei número 4.345-64.

$$
\text { Processo } n^{\circ} \text { 244-67 - COTIDE. }
$$

PESSOAL DO GRUPO OCUPACIONAL FISCO

Aplicabilidade do RETIDE.

Tendo em vista a leaislaçăo atinente à matéria, no Grupo Ocupacional Fisco, sòmente os cargos de direção e chefia náo privativos do referido arupo poderão ser incluídos em RETIDE.

Proçesso n॰ 96-66 - COTIDE, 


\section{PLANTÃO}

Auxiliar de Enfermagem incluido em RETIDE.

Na elaboração das escalas de serviço ou de plantão deve ser observado - minimo de 40 horas de trabalho semanais estabelecido no art. $6^{\circ}$ do $\mathrm{De}$ creto $\mathrm{n}^{2} 60.091-67$, sem prejuizo de atendimento ao que preceitua o referido dispositivo em sua parte final.

Processo $n^{2}$ 269-67 - COTIDE.

PODER JUDICIÁRIO

Inaplicabilidade do RETIDE ex-vi da Lei $n^{2} 4.345-64$ e do Decreto $n^{0}$ 60.091-67.

Referindo-se o art. 11 da Lei número 4.345-64 apenas aos funcionários do Serviço Civil do Poder Executivo, e cabendo à COTIDE zelar, tão-sòmente, pela aplicação do regime de tempo integral e dedicação exclusiva de que cogita o menciorfado dis rositivo (Decreto $n^{\circ}$ 60.091-67), escapa a esta Comissão competência legal para decidir pela extensibilidade do referido regime de trabalho a servidores do Poder Judiciário.

\section{Processo $n^{2}$ 543-67 - COTIDE.}

\section{PROCESSO ADMINISTRATIVO}

Integrante de Comissão de Processo Administrativo continua a te. ceber a gratificação.

Considerada a circunstância de que a designação de funcionário para participar de Comissão de Processo Administrativo constitui encargo obrigatório, seu afastamento do RETIDE não determina a sustação, no respectivo periodo, do pagamento da gratificação correspondente.

Tendo em vista, ainda, a peculiaridade das atribuições cometidas aos membros de tais Comissões, inclusive a possibilidade de funcionamento fora da repartição em que sirva ou sirvam alguns de seus integrantes, devem ficar êles isentos do ponto (Parecer do DASP no processo $\mathrm{n}^{\circ} 14.158-60$, in D. O. de 3-2-61).

Processo $n^{2} 342-67$ - COTIDE
PROCURAÇÃO

Têrmo de compromisso assinado por procuração.

Por analogia, e tendo em vista o que dispõe o art. 25 do Estatuto dos Funcionários (Lei 1.711-52), pode ser aceita a assinatura do têrmo de compromisso mediante procuração no caso de se encontrar o servidor incluido em RETIDE afastado da sede, em objeto de serviço.

$$
\text { Processo } n^{\circ} \text { 173-67 - COTIDE. }
$$

\section{RAIOS X}

Inaplicabilidade do RETIDE.

A vista do disposto no art. 34 do Decreto $\mathrm{n}^{\circ}$ 60.091-67, e considerada a circunstância de que, por imposição de regras de segurança e higiene do trabalho, os funcionários enquadrados no regime operacional de Raios X não podem atender ao número de horas semanais de trabalho (40 horas) exigido no art. $6^{\circ}$ do mencionado Decretó 17 60.091-67, torna-se impossivel a aplicação do RETIDE aos referidos servidores.

Processo $\mathrm{n}^{2}$ 940-67 - COTIDE.

\section{REDATORES}

Suta inclusão em regime de tempo integral e dedicação exclusiva.

Tendo em vista parecer emitido pela D.R.J.P. no processo n ${ }^{\circ}$ 580-66, aprovado pelo Sr. Diretor-Geral do DASP, foi decidida a inclusão de ocupante dé cargo de Redator em RETIDE.

Processo $n^{2}$ 236-67 C COTIDE.

\section{REGIME DISCIPLINAR}

Inaplicabilidade do art. 29 do Decreto $n^{\circ}$ 60.091-67 ao RESEX.

Tendo em vista os têrmos em que está expresso, e por cuidar de regime disciplinar, o art. 29 do Decreto número 60.091-67 só é aplicável àqueles a quem expressamente se refere. As infrações disciplinares praticadas por funcionário sujeito a serviço em horas extraordinárias devem correspon- 
der sanções enunciadas no capitulo próprio do Estatuto dos Funcionários.

Processo n' 391-66 - COTIDE.

\section{REPARTIÇÕES MILITARES COM HORÁRIO ESPECIAL}

Aplicabilidade do RETIDE.

A aplicação do regime de tempo integral nas unidades militares independe do horário de 44 horas semanais de trabalho ali $\mathrm{em}$ vigor, tendo em vista que se trata do regime de dedicação exclusiva.

Processo n* 981-66 - COTIDE.

\section{REMOÇన̃O}

Inclusão do funcionátio na tabela de RETIDE da nova repartiçāo.

O funcionário removido, transferido ou redistribuido só poderá ser incluido na tabela de RETIDE da repartição em que seja lotado se nesta existir cargo vago de igual denominação e nivel e atendidos os demais requisitos da regulamentação baixada com o Decreto $\mathrm{n}^{\circ} 60.091-67$.

\section{Processo n` 838-67 - COTIDE.}

REGIME ESPECIAL DE SERVIÇO EXTRAORDINÁRIO (RESEX)

Requisito para sua adoção.

O serviço extráordinário, em regime especial, previsto no art. $5^{\circ}$ do Decreto $n^{\circ}$ 60.091-67, está vinculado como complemento - ao regime de tempo integral e dedicação exclusiva de que cogita o mencionado decreto.

Assim, sòmente na repartição em que se aplique o RETIDE poderá ser processado o referido serviço extraordinârio.

Processo $n^{\circ}$ 391-66 - COTIDE.

A exigência de dedicação exclu siva nâo se estende ao RESEX.

O ônus da dedicação exclusiva, à vista dos têrmos do art. $2^{\circ}$ do Decreto $\mathrm{n}^{\circ}$ 57.744-66, refere-se, ùnicamente, aos abrangidos pelo art. $8^{\circ}$ do mesmo decreto, excluido, portanto, o pessoal a que se refere o art. $5^{\circ}$, isto é, os servidores que são submetidos ao serviço em horas extraordinárias.

Processo $n^{\circ}$ 391-66 - COTIDE.

Nota - O Decreto $\mathrm{n}^{2}$ 57.744-66 foi substituido pelo de $\mathrm{n}^{\circ} 60.091$. de 1967, o qual não alterou as normas a que se refere esta de. cisão.

Aplicabilidade de normas teferentes ao RETIDE.

O disposto no art. 14 do Decreto $\mathrm{n}^{\circ}$ 60.091-67, é aplicável, por extensão ao pessoal incluido no serviço extraordinário previsto no art. $5^{\circ}$ do citado decreto.

Processo $n^{\circ} 179-67$ - COTIDE.

Vigência para efeito de receb!mento da respectiva gratificaçăo.

Os efeitos pecuniários do serviço extraordinário, em regime especial, a que se refere 0 art. $5^{\circ}$ do Decreto $\mathrm{n}^{\circ}$ 60.091-67 só terão inicio, desde que publicada a respectiva portaria, quando tal serviço efetivamente começar.

Processo $\mathrm{n}^{\circ}$ 784-67 - COTIDE.

\section{REQUISITADO}

Sua inclusão $\mathrm{cm}$ RETIDE.

Para inclusão de servidor requisitado em regime de tempo integral e dedicação exclusiva devem ser observadas, além das normas gerais, as seguintes:

a) a repartição requisitante incluirá - cargo do funcionário indicado em sua proposta;

b) a portaria de inclusão será do dirigente ou responsável pela repartição requisitante;

c) o ônus da despesa, ressalvadas as hipóteses previstas no parágrafo único do art. 35 do Decreto número 60.091-67, caberá à repartição requisitante.

Processo $n^{\circ} 982-67$ - COTIDE. 


\section{SERVIÇO EXTERNO}

Fiscalização do cumprimento do horário e da execução do trabalho.

Desde que plenamente comprovada a necessidade de dispensa do "ponto" para o servidor em RETIDE e incumbido da execução de serviço externo, cabe a seu chefe imediato a responsabilidade de controlar, através de ficha própria, relatório ou outro processo de fiscalização, o cumprimento, pelo servidor, do horário de trabalho e a execução das tarefas que the estão cometidas.

Processo $\mathrm{n}^{\circ}$ 478-66 - COTIDE.

\section{SUBSTITUIÇÃO}

De ocupante de cargo em co. missão ou função gratificada.

Manifestando-se sôbre consultas at1nentes à matéria, formuladas nos processos ns. 337-66 e 853-67, a COTIDE esclareceu que:

a) nos afastamentos previstos no art. 14 do Decreto $\mathrm{n}^{\circ}$ 60.091-67, durante os quais o titular de cargo em comissão ou função gratificada não perde a gratificação, seu substituto não poderá recebê-la;

b) caso, porém, o afastamento não se enquadre no referido artigo 14 , o substituto fará jus à gratificação;

c) na substituição de titular de cargo em comissão ou função gratificada, afastado nas hipóteses do art. 14 do Decreto $n^{0} 60.091-67$, se seu substituto também se encontrar em RETIDE deverá receber 'apenas a gratificação de seu cargo e năo a do que substituir;

d) não poderá ser paga a gratificação do RESEX, previsto no art. $5^{\circ}$ do Decreto $\mathrm{n}^{\circ}$ 60.091-67, a servidor a êle vinculado, quando substituir titular de cargo em comissão ou função gratificada, colocada em RETIDE.

\section{TÊRMO DE COMPROMISSO}

Prazo para sua assinatura em relação à pottaria de inclusão no RETIDE.

Pronunciando-se sôbre consulta referente à aplicação do art. 23 e $\$ 1^{\circ}$ do Decreto $n^{*}$ 60.091-67, esclareceu COTIDE que, tendo em vista o dis- posto no art. 14 do citado decreto, a matéria encerra aspectos diversos, enquadráveis em duas hipóteses:

$\left.1^{\circ}\right)$ Servidor colocado em $R E$ TIDE pcla primeira vez ou que não haja participado dêsse regime no exercicio anterior - O servidor enquadrável em um dêsses dois casos e que se encontre afastado do serviço nos têrmos do art. 14 do Decreto $n^{\circ}$ 60.091-67 ou que dêle se afastar em data abrangida pelo prazo de 30 dias fixado no art. 27 do mesmo decreto, só poderá assinar o têrmo de compromisso a partir da data de sua reassunção, a contar da qual terá o referido prazo (30 dias) para fazê-lo;

2) Servidor convocado para RETIDE em exercicios consecutivos, isto é, sem que ocorra soluşão de continutidade - Se o - funcionário fôr reconvocado para nôvo periodo de trabalho em RETIDE. através da publicação da. competente portaria, e se encontrar afastado do serviço ou dềle tenha de se afastarve ou dos motivos previstos no por um do Decreto $\mathrm{n}^{\circ}$ 60.091-67, em data que se situe dentro do prazo de 30 dias de que cogita o art. 27 do referido decreto, poderá assinar o têrmo de compromisso, imediatamente, ou deixar para fazê-lo a partir do dia de sua reassunção, a contar do qual ainda poderá aproveitar o mencionado prazo para firmar o nôvo têrmo.

No primeiro caso, ou seja, na hipótese de o servidor assinar, de imediato, a nova op̧̧ão, passará a fazer jus à gratificação estabelecida na tabela a ela correspondente. Se, entretanto, o funcionário preferir adiar a assinatura do têrmo de compromisso para data posterior à reassunção, usando, assim, o prazo concedido no art. 27 , continuăá percebendo a gratificação fixada na tabela anterior.

$$
\text { Processo } n^{\circ} \text { 65-67 - COTIDE. }
$$

Obrigatoriedade de sua renovafrão no processamento de nôvo

Com o objetivo de preservar a caracterização da unidade de cada pro. 
grama, inclusive quanto às formalidades burocráticas, em proveito do contrôle e da fiscalização que, sôbre sua execução, poderão ser exercidos com maior rendimento, deve ser exigida a assinatura do têrmo previsto no artigo 26 do Decreto n ${ }^{\circ}$ 60.091-67.

Por outro lado, a prática de nova tomada de compromisso de todo o pessoal que participará das responsabilidades da execução de um plano a iniciar-se, manterá advertidos os funcionários em exercício nos Planos vigentes de que seus nomes serão discutidos para fins de aproveitamento em rôvo Plano, inclusive em função da maior ou menor operosidade com que se tenham havido na execução dos Planoś que se findam. Constitui tal prática um fator psicológico de résistência à burocratização ou estagnação do RETIDE, que vale preservar.

Processo $n^{\circ} 8-68-$ COTIDE.

\section{TRABALHO NOTURNO}

Sua conceituação com referência ao RESEX.

Para o fim de pagamento do acréscimo de $25 \%$ previsto no parágrafo único do Decreto $n^{\circ} 60.091,67$, deve ser considerado noturno, em analogia com o que preceitua $\circ \xi 2^{\circ}$ do artigo 73. da Consolidação das Leis do Trabalho, o serviço extraordinário, em regime especial, executado entre as 22 horas de um dia e as 5 horas do dia seguinte.

Processo n 964-67 - COTIDE.

\section{III - CIRCULARES EXPEDIDAS} A DIRIGENTES DE ORGAOS DA ADMINISTRAÇÃO (DIRETA OU INDIRETA), A PARTIR DE JUNHO DE 1967.

MODELOS DE PORTARIAS E TÊRMOS

\section{$N^{*} 152$, de 2.6-67}

Apresenta novos modelos de portarias para aplicação do Regime de Tempo Integral e Dedicação Exclusiva e para a cessação do referido regime, bem como para a elaboração de têrmos-de opção e de compromisso.

Ditos modelos, elaborados de acôrdo com o Decreto $\mathrm{n}^{\circ}$ 60.091, de
18-1-67, foram expedidos para subs. tituir os que vinham sendo usados des. de a vigência do Decreto 57.744-66.

\section{FISCALIZAÇÃO DE SERVIÇO EXTERNO}

$$
N^{\circ} \text { 157, de 20-6-67 }
$$

Solicita elementos e sugestões para a elaboração de novas normas destina. das ao processamento de maior contrôle e fiscalização da assiduidade, pontualidade $\mathrm{e}$ efetivo cumprimento dos honorários a que estão sujeitos os servidores vinculados ao regime de tempo integral e dedicação exclusiva, no caso de se incluir entre suas atribuições a prestação - normal ou even. tual - de serviço externo.

\section{FIXAÇÃO DO HORÁRIO}

$$
N^{\circ} \text { 228, de 11-9-67 }
$$

Solicita, com vista ao disposto no art. $6^{\circ}$ e seu $\S 1^{\circ}$, do Decreto número 60.091-67, combinado com o artigo 108 do Decreto-lei n* 200, do mesmo ano, que as repartições enviem à COTIDE, ao órgão central de pessoal do Ministério a que se subordinem e a Divisão de Segurança e Informaçóes cópias da portaria ou ordem de serviço que hajam fixado os horários de seus funcionários submetidos a RETIDE ou RESEX.

\section{PROPOSTA PARA TEMPO INTEGRAL EM 1968}

$N^{\circ} 229$, de 11-9-67

Encaminha Instruções Gerais calcadas no Decreto-lei $n^{2} 81-66$ e no Regulamento baixado com o Decreto número 60.091-67, destinadas a orientar a elaboração d’a proposta para a ado. ção, pelos órgãos interessados, do re. gime de tempo integral e dedicação exclusiva para o exercício de 1968.

\section{TÊRMO DE INSPEÇÃO}

$$
N \text { 45, de 5-3-68 }
$$

Envia aos Delegados Fiscais do Te. souro Nacional nos Estados modêlo de têrmo de inspeção a ser usado pelas Comissões que aquelas autoridades de. signem para o processamento, de acôr. 
do com o art. 31 do Decreto nŭmero 60.091-67, de inspeção nas repartições que apliquem o regime de que cogita o citado dispositivo.

\section{INSPEÇÃO A CARGO DOS ÓRGÃOS DE PESSOAL. \\ $N^{\circ}$ 57, de 13-3-68}

Endereçada aos dirigentes de órgãos de pessoal de repartições sediadas nos Estados e contendo, em anexo, a Circular 45-68 - encaminhada às Dele. gacias Fiscais do Tesouro - solicita aos destinatários que, como titulares de orgãos integrantes do sistema de fiscalização da execução do RETIDE, ex $-v i$ do art. 30 , item III, do respec. tivo Regulamento (Decreto $\mathrm{n}^{\circ} 60.091$ de 1967), se articulem com aquelas Delegacias, a fim de promoverem visi tas de inspeção.
Nesse expediente, a COTIDE também sugere às autoridades a que se dirige a aplicação dos têrmos de inspeção nas fiscalizações que realizem, solicitando-lhes, ainda, lhe dêem ciêncía dos resultados de tais inspeções.

\section{CONTENÇÃO DE DESPESAS \\ $N^{\text {ss }} 86$ e $86-\mathrm{A}$, de 19-4-68}

Respectivamente encaminhadas aos dirigentes dos setores de pessoal dos Ministérios e das Autarquias, solicitalhes a apresentação, no prazo de 15 dias, de novas tabelas para a adoção do RETIDE e do RESEX no corrente exercício, a fim de que possam ser fielmente observadas as medidas de compressão de despesa na aplicação dos mencionados regimes de trabalho, ditadas no Decreto $n^{0} 62.512$, de 9 de abril do ano em curso. 